\title{
EDUCAÇÃO EM SOLOS: UMA EXPERIÊNCIA PEDAGÓGICA COM ÊNFASE NA EROSÃO HÍDRICA DO SOLO
}

\author{
Cibele Stefanno Saldanha ${ }^{(a)}$, Tuane Telles Rodrigues ${ }^{(b)}$, Mauro Werlang ${ }^{(c)}$, Rodrigo Pontes ${ }^{(d)}$, \\ Letícia Ramires ${ }^{(e)}$
}

(a) Departamento de Geociências/ Universidade Federal de Santa Maria, Email:cibele2012stefanno@gmail.com

(b) Departamento de Geociências /Universidade Federal de Santa Maria, Email:tuanetel@ hotmail.com

(c) Departamento de Geociências /Universidade Federal de Santa Maria, Email: wermakwer@gmail.com

(d) Departamento de Geociências /Universidade Federal de Santa Maria, Email: rodrigocorreapontes@gmail.com

(e) Departamento de Geociências /Universidade Federal de Santa Maria, Email: leticiarcorrea@gmail.com

\section{EIXO: GEOGRAFIA FÍSICA: CURRÍCULO, FORMAÇÃO E PRÁTICAS DE ENSINO}

\begin{abstract}
Resumo
O solo desempenha um importante papel na regulação e equilíbrio ambiental.Nesta pesquisa o objetivo foi conduzir experimentos voltado aos processos da erosão hídrica, bem como conceito, tipos, modos de ocorrência do destacamento e transporte das partículas do solo com os educandos da turma 72 da Escola Municipal de Ensino Fundamental Euclides da Cunha localizada no município de Santa Maria,RS. Foram abordados temas relacionados a erosão hídrica o destacamento e transporte de materiais na forma de partículas do solo ou movimentos de massas do solo de um local para outro sobre a ação da chuva e do escoamento. Os efeitos negativos dela estão associados às regiões de equilíbrio delicado, cujo solo é muito susceptível a erosão. A falta de cobertura vegetal, juntamente com as características das precipitações, são fatores que interferem neste processo com intensidade e frequência. A pesquisa resultou-se que os educandos demonstraram através das atividades propostas domínio do conhecimento.
\end{abstract}

Palavras chave: Solos na Escola. Erosão. Cobertura Vegetal

\section{Introdução}

A falta de sensibilidade nas escolas e percepção da importância do solo vem sendo reproduzida. O espaço dedicado a este componente do sistema natural é freqüentemente nulo ou relegado a um plano menor nos conteúdos do ensino básico, tanto nas escolas urbanas como rurais. Os temas referentes a solos são ministrados de forma estanque, apenas enfatizando aspectos morfológicos sem relacioná-los com a dimensão ambiental (LIMA, 2002).

Os professores, tanto por falta de metodologia, assim como, por falta de conhecimento específico sobre o assunto, encontram dificuldades na abordagem dos conteúdos pedológicos no contexto ambiental, provocando a sua fragmentação e descontextualização, resultando no desinteresse de professores e alunos pelo tema. Não raramente, as escolas estão inseridas em um ambiente que pode ser amplamente utilizado 
para abordar o tema, mas por motivos diversos, como por exemplo, a falta de (re)conhecimento do espaço no entorno, essas possibilidades são desconsideradas, ou mesmo desconhecidas (MUGGLER et al, 2002).

O objetivo do trabalho demostram como ocorre a erosão hídrica do solo, enfatizando a importância da cobertura vegetal, mostrando duas situações diferentes como se dá a ação da água da chuva e no despreendimento de partículas e erosão do solo como: Tipos de erosão (eólica e hídrica); discutir os fatores que causam a erosão; discutir os efeitos da erosão do solo; discutir algumas práticas de controle e combate da erosão junto aos discentes na escola Euclides da Cunha.

A erosão é o arrastamento de partículas constituintes do solo, pela ação da água em movimento, resultantes da precipitação pluviométrica, ou pela ação dos ventos e das ondas (RIO GRANDE DO SUL, 1985). Isto quer dizer que um solo fértil, em que a erosão atua acentuadamente, em breve se tornará pobre, apresentando baixa produção agrícola ou florestal. Os dois agentes principais da erosão são as chuvas (erosão hídrica) e o vento (erosão eólica). No Brasil, a água é que causa os maiores prejuízos (FERREIRA, 1981).

O processo tende a se acelerar, à medida que mais terras são desmatadas para a exploração da madeira e/ou para a produção agrícola, uma vez que os solos ficam desprotegidos da cobertura vegetal (GUERRA, 1999).

Segundo Lima (2010), a erosão hídrica ocorre devido destacamento das partículas do solo pela ação da precipitação e do escoamento, acarretando o transporte das partículas para jusante onde se depositam podendo ser novamente destacadas.

Para Magalhães (2001), se desenvolve em quatro estágios: formação de canal onde há concentração de escoamento, incremento rápido em profundidade e largura onde a cabeceira move-se para montante, declínio do aumento com início de crescimento da vegetação natural, e eventual estabilização com o canal locado num perfil de equilíbrio com paredes estáveis e vegetação desenvolvida segurando o solo.

Como tipos têm- se: em profundidade, que de acordo com Magalhães (2001), acontece pela existência de um gradiente hidráulico; a superficial, onde segundo Carvalho et. al (2001), é provocada pela água de chuva, associada ou não aos processos de erosão interna e esqueletização; e a esqueletização, que segundo Roose (1977) surge por meio da dissolução de componentes minerais, provocando um aumento da porosidade do solo.

Ao analisar os Parâmetros Curriculares Nacionais (PCNs) aparentemente não há um ciclo específico no qual deva ser trabalhado este conteúdo. A morfologia deve ser encarada pelo professor como uma 


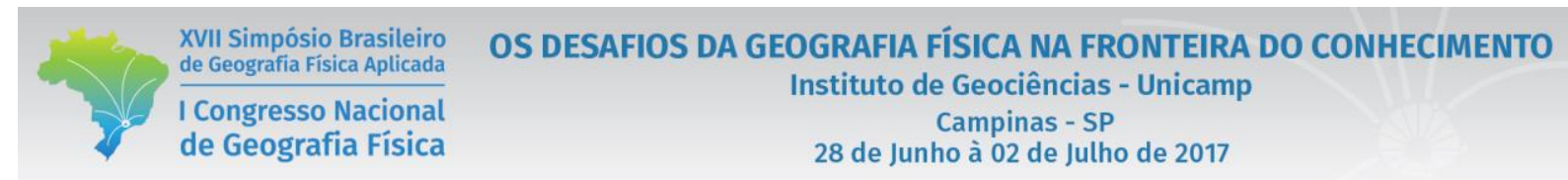

ferramenta didática que pode ser útil desde as mais elementares observações do primeiro e segundo ciclo do ensino fundamental (BRASIL, 1998), até estudos mais aprofundados no terceiro e quarto ciclo (BRASIL, 1998).

O estudo dos solos é de substancial importância para a sociedade. Segundo Reichardt (1978) devemos estudar o solo por diversos fatores, entre eles é necessidade de produzirmos alimentos, fibras, vegetais. Conseqüentemente devemos conservar o solo, ecossistemas e aqüíferos além de compreender processos que ocorre durante a formação e que ocorrem no solo durante o seu uso. No âmbito escolar, a ciência do solo assim como a geografia permite desenvolver atividades que possibilitam o conhecimento do solo e a interação aluno/professor.

Segundo Lima (2010), as principais intervenções de controle são: reduzir a agressividade do agente erosivo e da capacidade de transporte do escoamento, onde para alcançar esses objetivos se recorre as técnicas físicas, vegetativas e de retenção. Já para Magalhães (2001), as medidas preventivas consistem da adoção de um planejamento prévio em qualquer atividade ligada ao uso do solo. Diante do exposto, a relevância do estudo se traduz em demonstrar que um bom manejo do solo com a assistência de profissionais especializados em áreas que sejam grandes potencia para a ocorrência da erosão hídrica possibilita prevenir sua ocorrência.

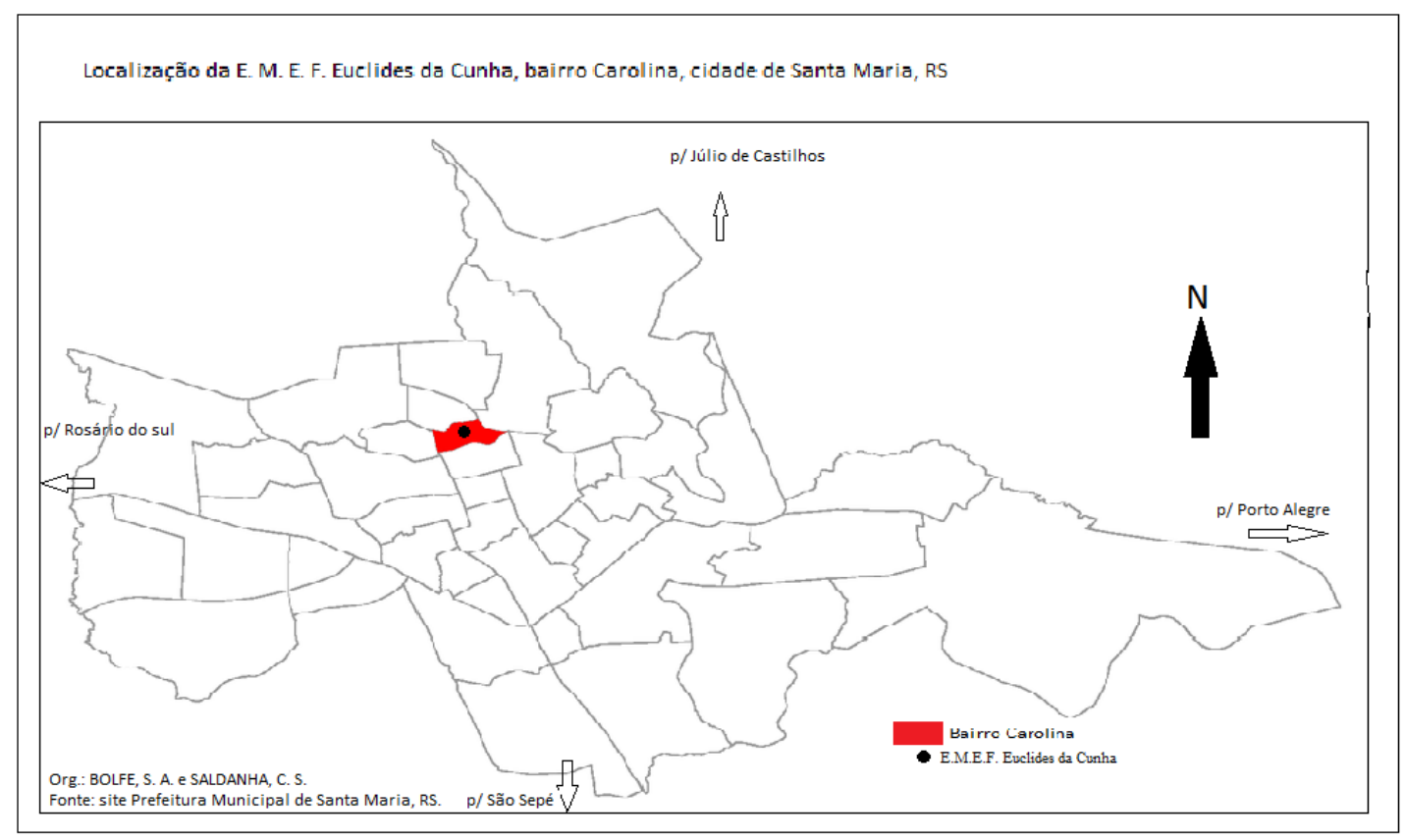

FIGURA 1-Localização da E. M.E.F. Euclides da Cunha, Santa Maria, RS. 
XVII Simpósio Brasileiro de Geografia Fisica Aplicada

I Congresso Nacional de Geografia Física
OS DESAFIOS DA GEOGRAFIA FÍSICA NA FRONTEIRA DO CONHECIMENTO

Instituto de Geociências - Unicamp

Campinas - SP

28 de Junho à 02 de Julho de 2017

\section{Metodologia}

A pesquisa foi realizada com o sétimo ano, turma 72, da Escola Municipal de Ensino Fundamental Euclides da Cunha, no terceiro trimestre avaliativo, nas aulas de Geografia, que ocorreram na sexta-seira, entre os dias 7 e 21 de Outubro de 2016.

Devido ao tempo disponibilizado pela direção da escola, tivemos seis aulas de 50 minutos cada. A turma possuía um total de vinte alunos matriculados. Para a professora titular da disciplina, este trabalho serviu como uma introdução a alguns temas que seriam abordados, segundo o cronograma da turma. Ao início da pesquisa, realizamos uma análise teórico-metodológica a fim de fornecer subsídios para a realização deste trabalho, bem como mostrar-nos a melhor forma de aproveitar as ferramentas que tínhamos a disposição.

A oficina pedagógica contará com uma aula expositiva introduzindo a temática referente à erosão hídrica e transporte de materiais na forma de partículas do solo e movimentos de massas do solo de um local para outro sobre a ação da chuva e do escoamento e a importância da cobertura vegetal e o que ocorre quando tem há falta dela.

Na segunda parte da oficina pedagógica será transportados até a escola Euclides da Cunha materias como: Duas garrafas PET de 2L, uma garrafa de $500 \mathrm{ml}$ com água, uma folhas A4, um torrão de solo com grama e um recipiente será coletado uma certa quantidade de solo no quintal da escola para realizar o experimento.

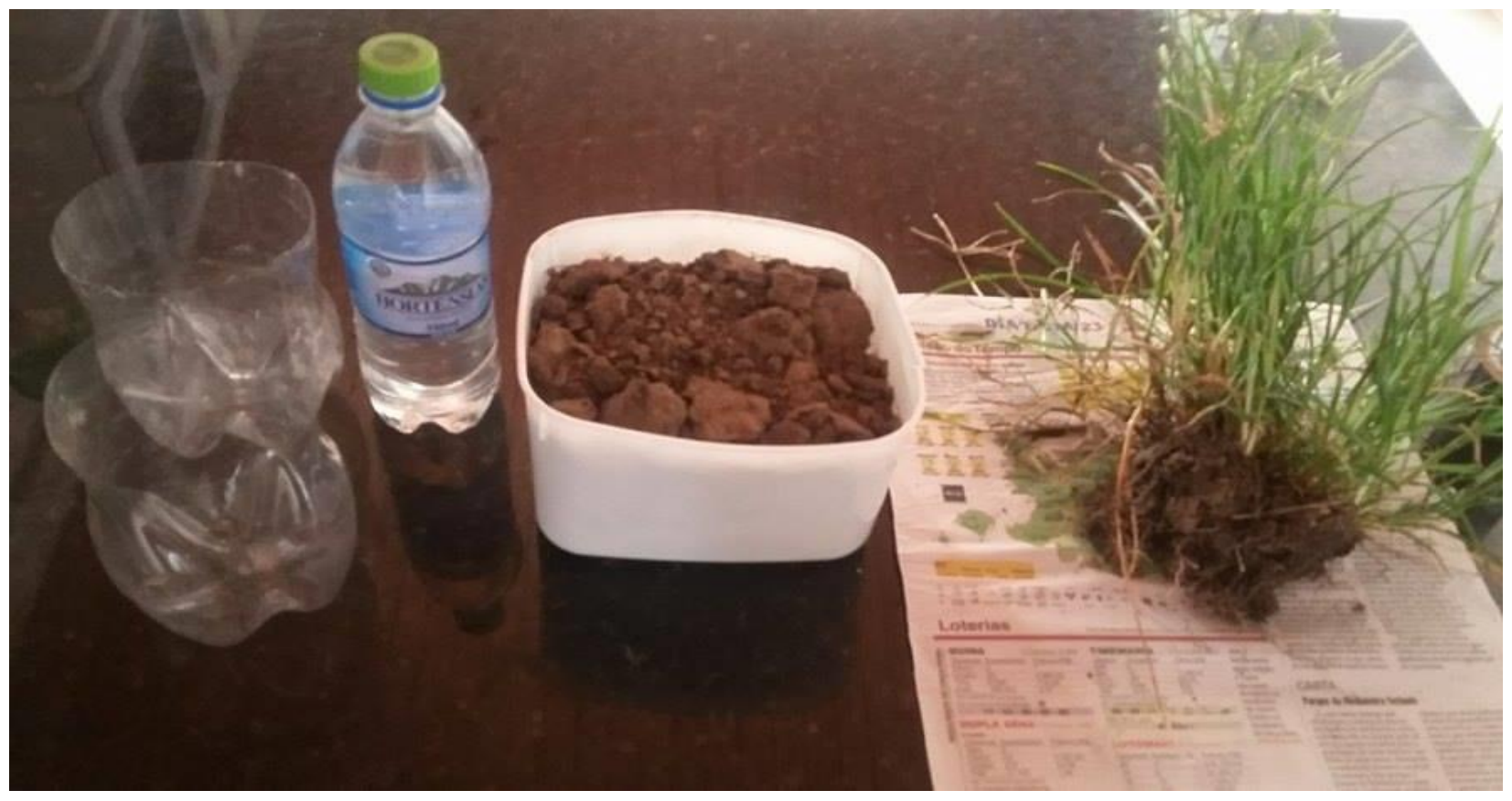

Figura 2 - Materiais utilizados no experiemento. 


$\begin{aligned} & \text { XVII Simpósio Brasileiro } \\ & \text { de Geografia Fisica Aplicada }\end{aligned}$
$\begin{aligned} & \text { I Congresso Nacional } \\ & \text { de Geografia Física }\end{aligned}$

\section{Resultados e Discussões}

Pode-se observar que a utilização de recursos didáticos selecionados adequadamente, surge efeito positivo no processo de ensino-aprendizagem. Trata-se de experimentos simples que ressaltam conceitos como erosão e a importância do solo.

Diante da concessão da direção escolar para execução do projeto o início das atividades ocorreu com uma conversa sobre a apresentação do projeto aos alunos, sujeitos da pesquisa e a direção da Euclides da Cunha. O projeto iniciou com a apresentação das temáticas abordadas durante a experimentoteca.

A experimentoteca foi uma aula teórica e expositiva onde foi realizada abordagem sobre alguns conceitos básicos sobre a erosão hídrica e transporte de materiais do solo e movimentos de massas do solo, ação da chuva do escoamento e a importância da cobertura vegetal, inicialmente os educando acharam a atividade complexa, devido aos temas que seriam trabalhadas, entretanto os educando interagiram, e tiveram um apreendizado prático e teórico. A primeira parte do experimento contou com as garrafas PET cortadas já com amostras de solo e ambas as garrafas, em apenas foi retirado do quintal da escola um fragmento de grama representando a presença do solo com cobertura vegetal e um solo sem a presence da vegetação. Como mostra a figura 3 logo abaixo.

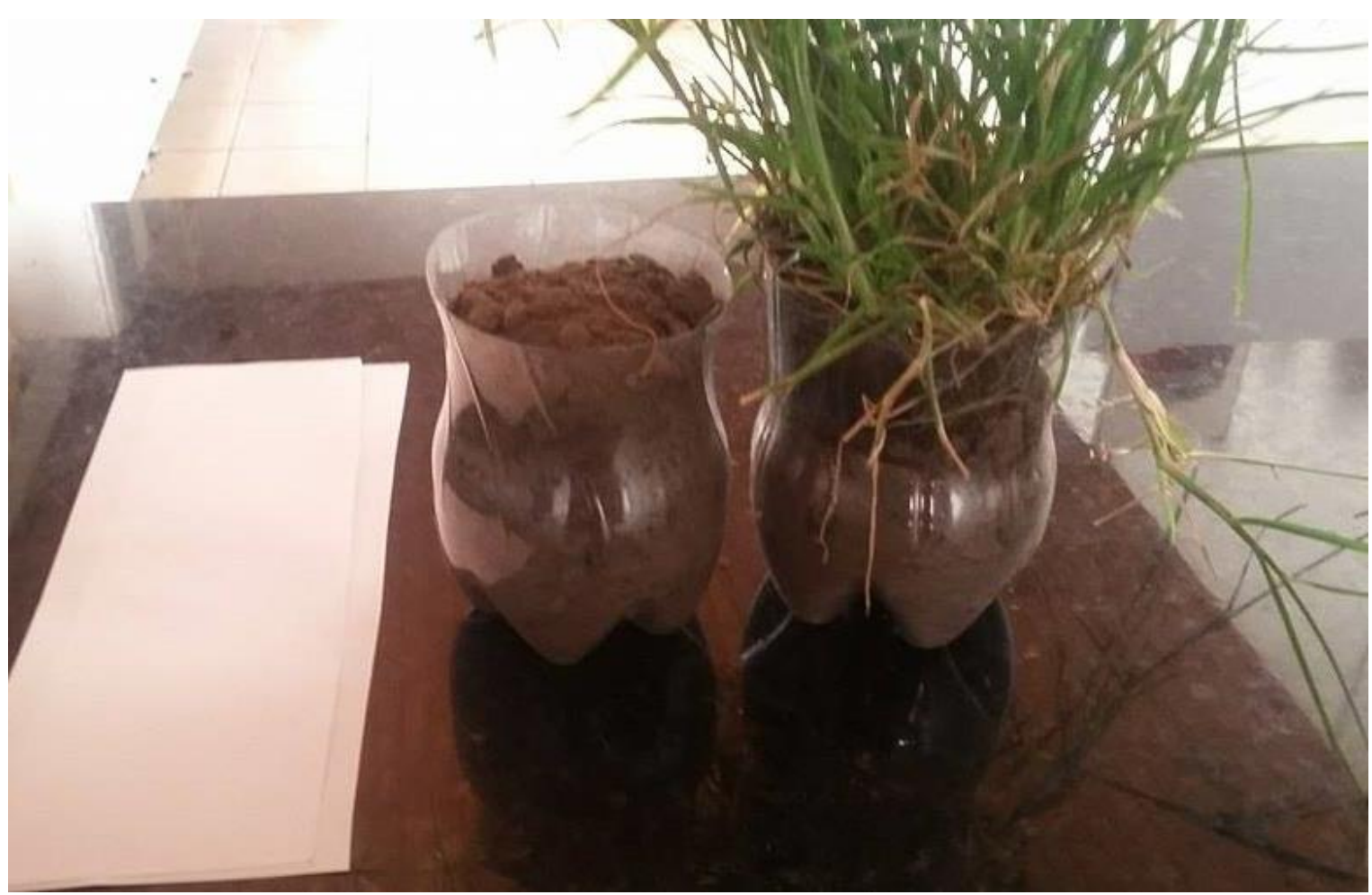

Figura 3- Materiais utilizados no experiemento. 


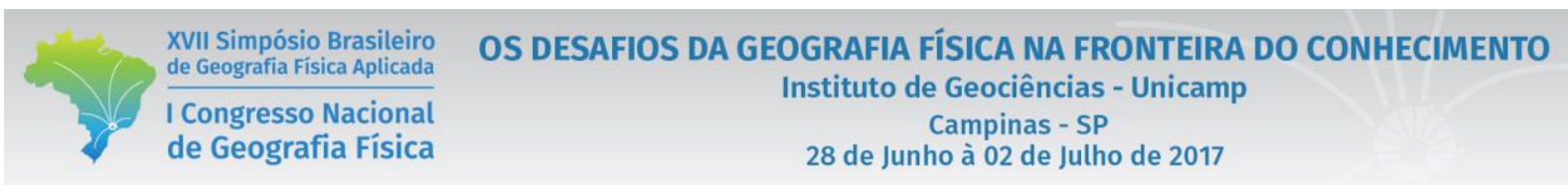

A segunda parte da experimentoteca os educandos colocaram ao redor da garrafa uma fita de papel, em seguida pegaram uma garrafa com água e colocaram uma pequena quantidade de água sob o as amostras de solos, a figura 3 mostra os dois recipientes o 1 e o 2 , no recipiente 1 tem apenas solo exposto com a fita, no recipiente 2 ilustra um solo com a presença de vegetação a fita domostrou qual das duas amostras sofrem maior deperda de solo e nutrientes atravéz a erosão hídrica que ocorre de forma distinta entre as amostras.

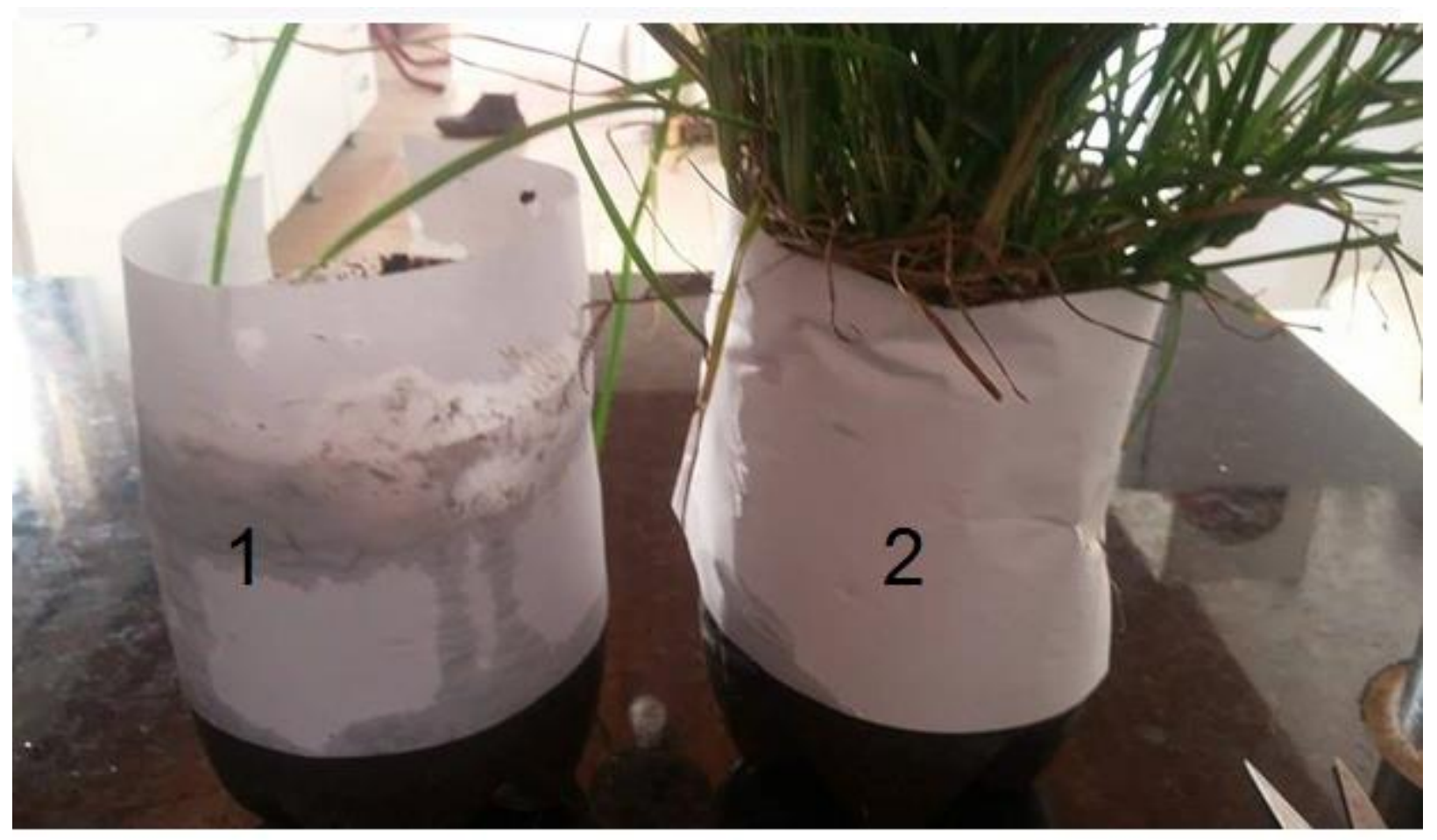

Figura 3 - Amostras utilizas no experiemento.

A imagem 5 mostra como ocorreu processo de erosão hídrica nas diferentes amostras conforme as fitas, ao analisar o experimento através das fitas os educandos chegaram a conclusão que o recipiente 1 que havia apenas a presença de solo exposto teve uma perda de solo significativa com a presença da água que ilustrou a presipitação pluviométrica, já no recipiente 2 a fita saiu praticanente limpa, ou seja, o solo que possui algum tipo de cobertura vegetal o processo de erosão e transporte de materiais na forma de partículas do solo, tanto pela chuva ou escoamento não é tão agressivo. Como mostra figura 5 abaixo. 

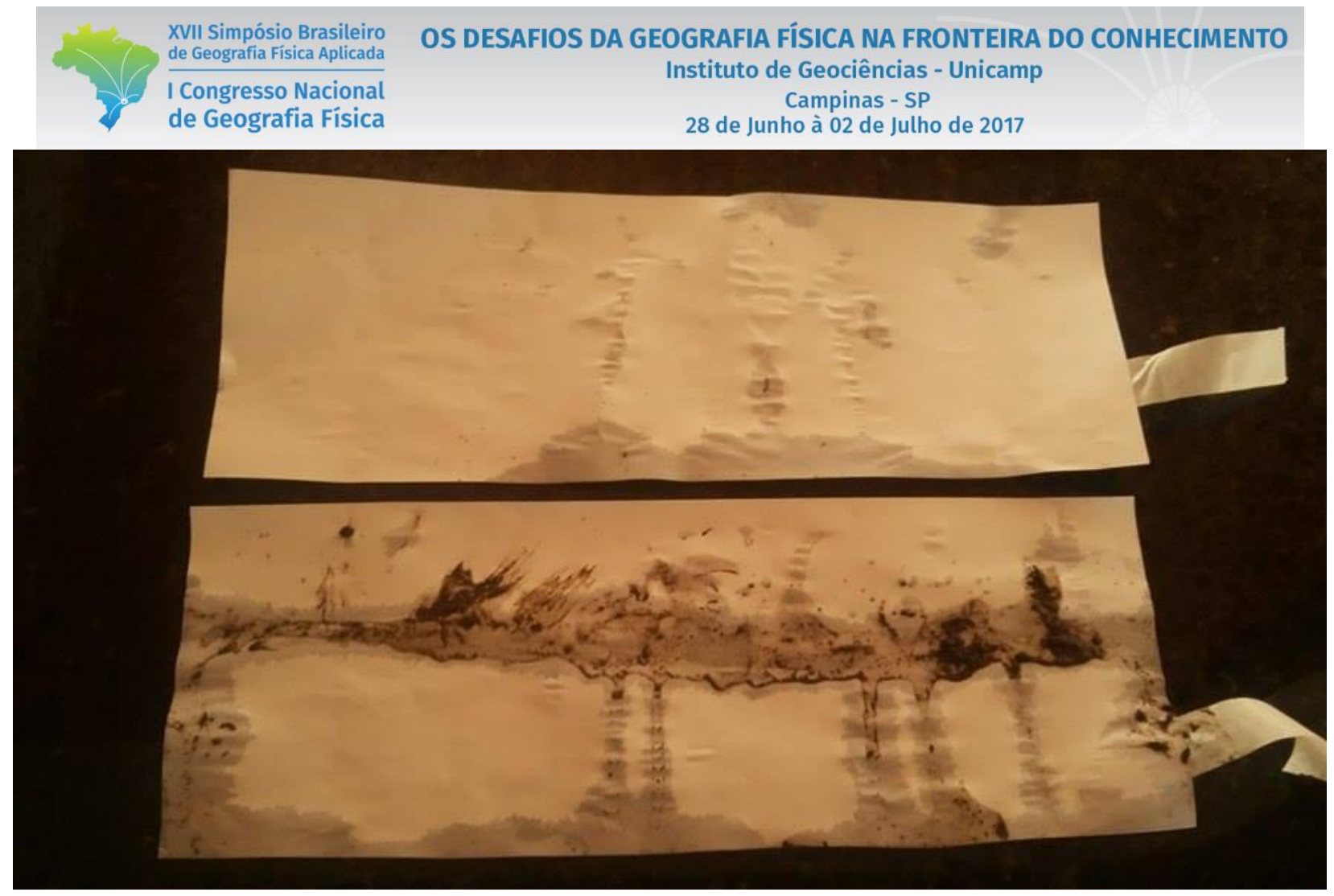

Figura 5 - Fitas utilizados no experiemento.

Os alunos devem perceber que o ser humano pode transformar e conter os processos naturais através do preparo do cultivo, quais as técnicas para combater a erosão, manejo da água, etc. O professor de geografia deve afirmar a importância da cobertura vegetal (neste experimento demonstrado pela grama), como as florestas que formam uma barreira contra os ventos e a queda direta da água da chuva, e esclarecer que além deste e outros fatores, a erosão está intimamente relacionada com a topografia (relevos mais ondulados) e as condições atmosféricas (direção e intensidade dos ventos, etc).

\section{Conclusão}

Diante dos resultados obtidos, a partir do desenvolvimento da experiemtoteca com os alunos do $7^{\circ}$ ano da turma 72 da Escola Municipal de Ensino Fundamental Euclides da Cunha, Santa Maria, RS conclui-se que a experimetoteca alcançou o objetivo e corrobora com as palavras de Piaget (1974, p. 35) "[...] falar em educação é, em primeiro lugar, reconhecer o papel indispensável dos fatores sociais na própria formação do indivíduo". Para ele, a escola é o local no qual o educando deve encontrar possibilidades de construir seu conhecimento, formando indivíduos com autonomia intelectual e moral, respeitando a autonomia dos outros.

Portanto, a proposta apresentada e desenvolvida pretende promover nos alunos o despertar a construir seu conhecimento e a vinculá-lo ás experiências vividas por eles. É um desafio que culmina no objetivo maior da educação: formar cidadãos ativos e comprometidos, a pesquisa atingiu seus objetivos. 
Dessa forma pode-se avaliar que os alunos, de um modo geral, tiveram uma boa compreensão do conteúdo abordado, indicando que foi positiva a discussão dos conceitos previstos durante a oficina. Considerou-se que a experimetoteca alcançou o resultado proposto a partir do tema abordado. Considera-se, portanto que o conhecimento não é dado e sim construído pelos alunos e pelo professor em sala de aula, em uma relação recíproca que nunca vai acabar ou chegar a um fim.

Para os alunos do ensino fundamental, segundo os Parâmetros Curriculares Nacionais (PCNs) (BRASIL, 1998) deve-se investigar com o auxílio do professor que os recursos disponíveis na terra como o solo, pode ser reduzido drasticamente pelo seu uso exagerado, inadvertido ou deliberado, prejudicando nas atividades agrosilvipastoris e no desenvolvimento da sociedade humana. O professor de geografia tem o dever de veicular aos educandos sobre os custos da restauração dos ambientes degradados, ressaltando a importância das práticas de preservação e uso do solo.

\section{REFERÊNCIAS}

BRASIL. Secretaria de Educação Fundamental. Parâmetros curriculares nacionais: terceiro e quarto ciclos, apresentação dos temas transversais. Brasília : MEC/SEF, 1998.

FERREIRA, P. H. de M.; Princípios de manejo e conservação do solo. 2. ed. São Paulo: Nobel, 1981.

GUERRA, A.J.T.; SILVA, A.S. da; BOTELHO, R.G.M. Erosão e conservação dos solos: conceitos, temas e aplicações. Rio de Janeiro: Bertrand Brasil, 1999. 340 p.

RIO GRANDE DO SUL. Secretaria da Agricultura. Manual de conservação do solo e água: uso adequado e preservação dos recursos naturais renováveis. 3. ed. atualizada. Porto Alegre, 1985. 287 p.

LIMA, Herlander Mata. Introdução à Modelação Ambiental: Erosão Hídrica. Funchal (Portugal), 2010.

LIMA, M. R. O solo no ensino fundamental: situação e proposições. Curitiba: Universidade Federal do Paraná, Departamento de Solos e Engenharia Agrícola, 2002. 33 p.

MAGALHÃES, Ricardo Aguiar. Erosão: Definições, Tipos e Formas de Controle. VII Simpósio Nacional de Controle de Erosão. Goiânia- GO, 03 a 06 de maio de 2001.

MUGLlER, C. C.; SOBRINHO, F. A.; MACHADO, V. A. Educação em solos: princípios, teoria e métodos. Revista Brasileira de Ciência do Solo, Viçosa, n. 4, v. 30, Julho - agosto. 2006.

REICHARDT, K. Porque estudar os solos? Congresso Brasileiro de Ciência do Solo, 1988, Campinas. Anais de congresso em CD-ROM.

ROOSE, E. (1997). Erosion et Ruissellement em Afrique de L'Ouest, Traveaux et Documents de l'O.R.S.T.O.M, $\mathrm{n}^{\circ}$ 78. Paris.

LIMA, M. R. O solo no ensino fundamental: situação e proposições. Curitiba: Universidade Federal do Paraná, Departamento de Solos e Engenharia Agrícola, 2002.33 p. 